\title{
Vortex Motion in Axisymmetric Piston-Cylinder Configurations
}

\author{
Tom I-P. Shih, ${ }^{*}$ Gene E. Smith, $\dagger$ and George S. Springer $\ddagger$ \\ The University of Michigan, Ann Arbor, Michigan
}

\begin{abstract}
$\mathbf{F}$ LUID motion inside cylinders of reciprocating piston engines has been studied by both experimental and numerical methods. ${ }^{1,2}$ These investigations have revealed that recirculating flows (vortices) form during the intake stroke. Under some conditions these vortices may persist throughout the compression stroke ${ }^{2}$ and seriously affect the ignition and flame propagation processes. Since these vortices can play such an important role in the combustion process, their formation, growth, and break-up during the intake stroke, and their subsequent behavior during the compression stroke need to be understood. Most of the previous studies focused only on the problem of vortex motion during the intake stroke. Relatively little is known about the behavior of vortices during the compression stroke. This investigation was addressed, therefore, to the study of vortex motion during the compression stroke of those vortices that form during the intake stroke. To accomplish this, velocities were calculated inside axisymmetric piston-cylinder configurations. The velocity fields were presented in graphical form which illustrate the formation, growth, and break-up of the vortices.
\end{abstract}

\section{Contents}

The following problem was analyzed. A hollow circular cylinder is closed on one end by a flat piston and on the other end by a flat plate (Fig. 1). The piston is connected to a crank shaft through a connecting rod. The flat plate has a centrally located annular opening (valve opening) in it which opens instantaneously at the beginning of the intake stroke (crank angle $\phi=0$ ) and closes instantaneously at the end of the intake stroke $(\phi=\pi)$. The temperatures at the cylinder wall, valve, cylinder head, and piston are constants, but may have different values.

The fluid enters the piston-cylinder configuration just described through the valve opening during the intake stroke. The stagnation temperature $T_{i}$ and stagnation pressure $P_{i}$ of the entering fluid are both taken to be constants. At the valve opening, the entering fluid may have velocity components in the radial and axial directions but not in the tangential direction. The viscous and thermally conducting fluid which enters the cylinder is an ideal gas having constant thermodynamic and transport properties.

At the beginning of the intake stroke, the gas in the clearance volume (residual gas) is taken to be a stagnant, ideal

Received Feb. 26, 1982; synoptic submitted June 22, 1983. This paper is declared a work of the U.S. Government and therefore is in the public domain. Full paper available from National Technical Information Service, Springfield, Va., 22151 at the standard price (available upon request).

${ }^{*}$ Graduate Student, Department of Mechanical Engineering and Applied Mechanics; presently Assistant Professor, Department of Mechanical Engineering, University of Florida. Member AIAA.

$\nmid$ Professor, Department of Mechanical Engineering and Applied Mechanics.

$\ddagger$ Professor, Department of Mechanical Engineering and Applied Mechanics. Associate Fellow AIAA. gas at stagnation temperature $T_{i}$ and stagnation pressure $P_{c}$ $\left(P_{c} \leq P_{i}\right)$. The residual gas has the same thermodynamic and transport properties as the intake charge.

The governing equations for the problem just described are the conservation equations of mass, radial momentum, axial momentum, and energy. The conservation equations employed were those valid for unsteady compressible laminar flows. Recent evidence suggests that the type of turbulence model employed in the analysis does not affect significantly the calculated flow patterns. ${ }^{3}$ For this reason the increased mixing due to turbulence was simulated in a simple and convenient manner by choosing appropriate values of the effective transport properties. Solutions to the governing equations were obtained by the implicit factored, finite difference method of Beam and Warming. ${ }^{4}$ Readers are referred to Refs. 5 and 6 for the details of the solution procedures. Calculations were performed to explore the vortex motion inside the cylinder during the intake and compression strokes. Only typical results are presented here which illustrate the major features of the flow pattern.

During the intake stroke, two toroidal vortices were formed by the vorticity generated by the jet at the valve opening and the adverse pressure gradients produced by the jet impinging on the piston surface (Fig. 2). One of these vortices was located between the jet and the cylinder wall (cylinder-head vortex). The other was located between the jet and the centerline (valve vortex). The formation and subsequent motion of these vortices during the intake stroke were found to be consistent with those observed in previous experimental and numerical studies. ${ }^{1-3,7,9}$

However, the present results showed one phenomenon during the intake stroke that has not been reported previously. At bore-to-stroke ratio of less than unity, the cylinder-head vortex broke up into two smaller vortices. The break-up was caused by interaction of the valve and cylinder-head vortices.

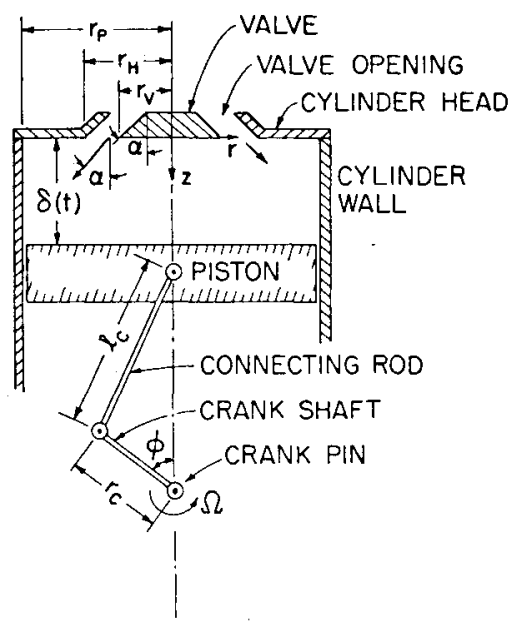

Fig. 1 Geometry used in the present study. 

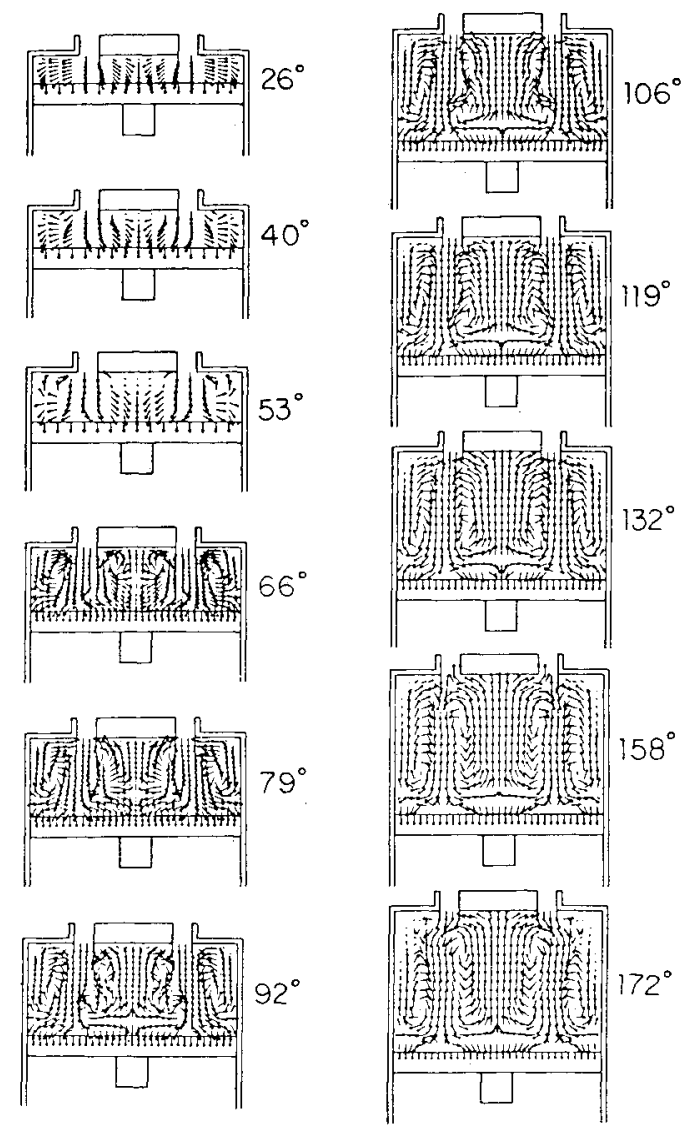

Fig. 2 Flow patterns during the intake stroke as a function of crank angle from top dead center: $r_{p} / r_{c}=1.67, \Omega=400 \mathrm{rpm}, P_{i} / P_{c}=1$ and $\alpha=0$ deg.

Ekchian and Hoult ${ }^{7}$ also noted vortex break-up in their tests with water injected into a circular cylinder. However, in Ekchian and Hoult's experiments, the vortex break-up was due to flow instability and not to vortex interaction. In their experiments the vortex broke up and then degenerated into a random flow. In the present study the vortex did not degenerate into a random flow because flow instability and three-dimensional flow (needed for the complete vortex break-up) were not included in the numerical solution.

During the intake stroke, the jet separated the cylinder-head and valve vortices minimizing the interaction between them (Fig. 2). During the compression stroke, the cylinder-head and valve vortices were no longer separated by the jet, allowing the two vortices to interact. Because of the rotational motion of the two vortices, they forced each other toward the piston. Since the two vortices were of unequal strength, the weaker one was pushed closer to the piston surface by the stronger one.

As the piston speed increased during the compression stroke (crank angle $\phi$ between 190 and $240 \mathrm{deg}$ ), the two vortices began to coalesce (Fig. 3). Coalesce as used here means combinc, by entrainment. The time of this coalescing depended upon the strength of the vortex that was nearer to the piston surface.

At crank angles $\phi$ between 230 and $240 \mathrm{deg}$, the two vortices coalesced into a single toroidal vortex (Fig. 3 ). The coalescing of the cylinder-head and valve vortices has not been described by previous investigators.

Toward the end of the compression stroke (crank angle $\phi>320 \mathrm{deg}$ ) a new recirculating flow (corner vortex) formed in the corner of the clinder-head and cylinder wall (Fig. 3). The formation of the corner vortex has been reported previously. ${ }^{8,9}$
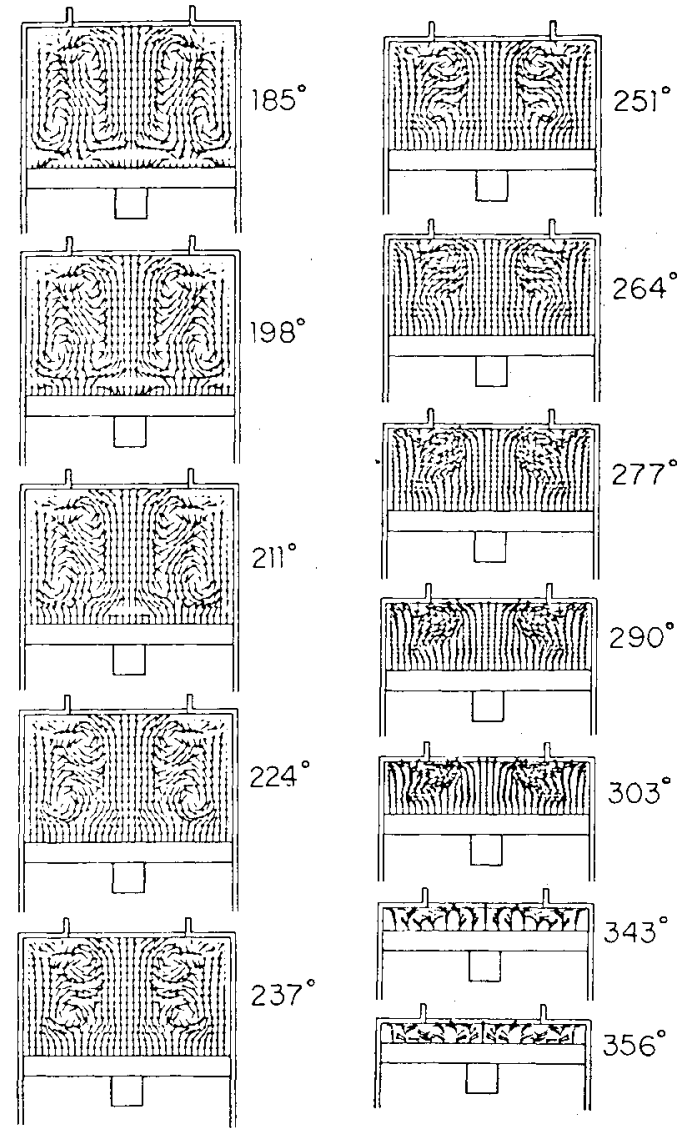

Fig. 3 Flow patterns during the compression stroke as a function of crank angle from top dead center: $r_{p} / r_{c}=1.67, \Omega=400 \mathrm{rpm}$, $P_{i} / P_{c}=1$, and $\alpha=0$ deg.

\section{Acknowledgment}

The authors are grateful to NASA Lewis Research Center for providing the computer time and the use of their computing facilities.

\section{References}

${ }^{1}$ Mattavi, J. N. and Amann, C. A., eds., Combustion Modelling in Reciprocating Engines, Plenum Press, New York, 1980.

${ }^{2}$ Witze, P. O., ed., "Comparisons between Measurement and Analysis of Fluid Motion in Internal Combustion Engines," Sandia National Laboratories, Livermore, Calif., SAND 81-8242, Oct. 1981.

${ }^{3}$ Schock, H. J., Sosoka, D., and Ramos, J. I., "Numerical Studies of the Formation and Destruction of Vortices in a Four-Stroke PistonCylinder Configuration," AIAA Paper 83-0497, 1983.

${ }^{4}$ Beam, R. M. and Warming, R. F., "An Implicit Factored Scheme for the Compressible Navier-Stokes Equations," AIAA Journal, Vol. 16,1978 , pp. 393-402.

${ }^{5}$ Shih, T. I-P., "Application of the Implicit Factored Method to Complex Flow Problems,"' Ph.D. Thesis, Department of Mechanical Engineering and Applied Mechanics, The University of Michigan, Ann Arbor, Mich., 1981.

${ }^{6}$ Shih, T. I-P., Smith, G. E., Springer, G. S., and Rimon, Y., "Boundary Conditions for the Solution of Compressible NavierStokes Equations by an Implicit Factored Method," Journal of Computational Physics, Vol. 52, 1983, pp. 54-79.

${ }^{7}$ Ekchian, A. and Hoult, D. P.. "Flow Visualization Studies in an Internal Combustion Engine," SAE Paper 790095, 1979.

${ }^{8}$ Chong, M. S. , Milkins, E. E., and Watson, H. C., "Predictions of Heat and Mass Transfer during Compression and Expansion in I.C. Engines," SAE Paper 760761, 1976.

${ }^{9}$ Gosman, A. D., Johns, R.J.R., and Watkins, A. P. "Development of Prediction Methods for In-Cylinder Processes in Reciprocating Engines," Combustion Modeling in Reciprocating Engines, edited by J. N. Mattavi and C. A. Amann, Plenum Press, New York, 1980, pp. 69-129. 